\title{
Article \\ Calculated Plasma Volume Status Is Associated with Adverse Outcomes in Patients Undergoing Transcatheter Aortic Valve Implantation
}

\author{
Hatim Seoudy 1,2, ${ }^{\dagger}$, Mohammed Saad ${ }^{1,+}{ }^{\text {, }}$ Mostafa Salem ${ }^{1}$, Kassem Allouch ${ }^{1}$, Johanne Frank ${ }^{1,2}$,

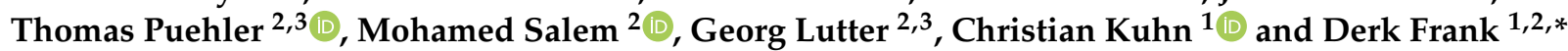 \\ 1 Department of Internal Medicine III, Cardiology and Angiology, Campus Kiel, University Hospital \\ Schleswig-Holstein, D-24105 Kiel, Germany; hatim.seoudy@uksh.de (H.S.); mohammed.saad@uksh.de (M.S.); \\ mostafa.salem@uksh.de (M.S.); kassem.allouch@gmx.de (K.A.); johanne.frank@uksh.de (J.F.); \\ chris_kuhn@gmx.de (C.K.) \\ 2 DZHK (German Centre for Cardiovascular Research), Partner Site Hamburg/Kiel/Lübeck, \\ D-24105 Kiel, Germany; thomas.puehler@uksh.de (T.P.); mohamed.salem@uksh.de (M.S.); \\ georg.lutter@uksh.de (G.L.) \\ 3 Department of Cardiac and Vascular Surgery, Campus Kiel, University Hospital Schleswig-Holstein, \\ D-24105 Kiel, Germany \\ * Correspondence: derk.frank@uksh.de; Tel.: +49-(0)4-31500-22801 \\ + These authors have contributed equally to this work and share first authorship.
}

\section{check for} updates

Citation: Seoudy, H.; Saad, M.; Salem, M.; Allouch, K.; Frank, J.; Puehler, T.; Salem, M.; Lutter, G.; Kuhn, C.; Frank, D. Calculated Plasma Volume Status Is Associated with Adverse Outcomes in Patients Undergoing Transcatheter Aortic Valve Implantation. J. Clin. Med. 2021, 10, 3333. https://doi.org/10.3390/ jcm10153333

Academic Editor: Fabio Mangiacapra

Received: 23 June 2021

Accepted: 28 July 2021

Published: 28 July 2021

Publisher's Note: MDPI stays neutral with regard to jurisdictional claims in published maps and institutional affiliations.

Copyright: (c) 2021 by the authors. Licensee MDPI, Basel, Switzerland. This article is an open access article distributed under the terms and conditions of the Creative Commons Attribution (CC BY) license (https:// creativecommons.org/licenses/by/ $4.0 /)$.

\begin{abstract}
Background: Calculated plasma volume status (PVS) reflects volume overload based on the deviation of the estimated plasma volume (ePV) from the ideal plasma volume (iPV). Calculated PVS is associated with prognosis in the context of heart failure. This single-center study investigated the prognostic impact of PVS in patients undergoing transcatheter aortic valve implantation (TAVI). Methods: A total of 859 TAVI patients had been prospectively enrolled in an observational study and were included in the analysis. An optimal cutoff for PVS of $-5.4 \%$ was determined by receiver operating characteristic curve analysis. The primary endpoint was a composite of all-cause mortality or heart failure hospitalization within 1 year after TAVI. Results: A total of 324 patients had a PVS $<-5.4 \%$ (no congestion), while 535 patients showed a PVS $\geq-5.4 \%$ (congestion). The primary endpoint occurred more frequently in patients with a PVS $\geq-5.4 \%$ compared to patients with PVS $<-5.4 \%$ (22.6\% vs. $13.0 \%, p<0.001)$. After multivariable adjustment, PVS was confirmed as a significant predictor of the primary endpoint (HR 1.53, 95\% CI 1.05-2.22, $p=0.026$ ). Conclusions: Elevated PVS, as a marker of subclinical congestion, is significantly associated with all-cause mortality and heart failure hospitalization within 1 year after TAVI.
\end{abstract}

Keywords: aortic stenosis; transcatheter aortic valve implantation; valvular heart disease; congestion; plasma volume; risk stratification

\section{Introduction}

Transcatheter aortic valve implantation (TAVI) has become an essential treatment option for severe aortic stenosis (AS) across the whole spectrum of surgical risk [1,2]. In patients undergoing TAVI, subclinical congestion is associated with worse clinical outcomes. However, it is often not detected by routine clinical assessment [3]. While right heart catheterization is considered the gold standard to quantify fluid status in patients with volume overload, its use is limited by its invasive nature [4]. Radiotracer indicatordilution methods using labeled albumin or red blood cells were previously proposed as alternative techniques to accurately quantify plasma volume (PV), but are not applicable in daily clinical practice $[5,6]$. In contrast, non-invasive PV calculations based on weight and hematocrit have been shown to correlate well with quantitative measurements using gold-standard radioisotope assays [7]. Plasma volume status (PVS) reflects the degree of 
deviation of the estimated plasma volume (ePV) from the ideal plasma volume (iPV) and has been shown to be associated with prognosis in patients with heart failure [8].

The aim of this study was to determine the incidence and prognostic impact of subclinical volume overload, detected by elevated calculated PVS, in patients undergoing TAVI. We hypothesized that PVS is significantly associated with adverse outcomes after TAVI.

\section{Materials and Methods}

Between February 2014 and February 2020, a total of 979 patients undergoing transfemoral TAVI were prospectively enrolled in an observational study at the University Hospital Schleswig-Holstein, Kiel, Germany. Patients with incomplete clinical or follow-up data as well as those with intraprocedural conversion to open-heart surgery were excluded from the analysis. The final study population comprised 859 patients.

An optimal PVS cutoff value of $-5.4 \%$ (AUC $0.601,95 \%$ confidence interval $0.55-0.65$, $p<0.001$ ) was determined using receiver operating characteristic (ROC) curve analysis. According to calculated PVS, patients were divided into two groups: PVS $<-5.4 \%$ (no congestion) versus PVS $\geq-5.4 \%$ (congestion). The primary endpoint was a composite of all-cause mortality or heart failure hospitalization. The secondary study endpoints were both individual components of the primary endpoint.

The decision to perform TAVI was based on careful evaluation by the multidisciplinary heart team. All procedures were performed using third-generation SAPIEN devices (Edwards Lifesciences, Irvine, CA, USA) or CoreValve devices (Medtronic, Minneapolis, MN, USA). Type and size of the transcatheter heart valve were determined using pre-procedural multidetector computed tomography measurements and evaluation with the 3 mensio Structural Heart software (3 mensio Medical Imaging BV, Bilthoven, the Netherlands). Procedures were done by experienced implanters and pre- and post-dilatation were left to the physician's discretion. During TAVI, unfractionated heparin was administered to achieve an activated clotting time of 250-300 s. Closure of the vascular access was conducted using two Perclose ProGlide ${ }^{\mathrm{TM}}$ vascular closure systems (Abbott Laboratories, Chicago, IL, USA).

PVS was calculated after obtaining ePV and iPV using two well-established equations which have been previously reported in detail elsewhere $[9,10]$ :

$$
\mathrm{ePV}=((1-\text { hematocrit }) \times(\mathrm{a}+(\mathrm{b} \times \text { weight }(\mathrm{kg})))),
$$

with $\mathrm{a}=864$ in females and 1530 in males, and $\mathrm{b}=47.9$ in females and 41 in males.

$$
\mathrm{iPV}=\mathrm{k} \times \text { weight }[\mathrm{kg}] \text {, with } \mathrm{k}=40 \text { in females and } 39 \text { in males. }
$$

PVS is an index of deviation of ePV from iPV and was subsequently calculated as follows:

$$
\text { PVS }=((\mathrm{ePV}-\mathrm{iPV}) \times 100 \%) / \mathrm{iPV}
$$

Written informed consent was obtained from each patient. The study was approved by the Ethics Committee of the University of Kiel and conformed to the ethical guidelines of the Declaration of Helsinki. Patient data and blood samples were collected 1-3 days prior to TAVI. Patients were followed up through clinical visits, communication with ambulatory physicians, or telephone consultations after the procedure. Patient outcomes were reported according to the incidence of life-threatening bleeding, myocardial infarction, stroke with disability, acute kidney injury stage $3 / 4$, and new permanent pacemaker implantation in accordance with the definitions of the Valve Academic Research Consortium-3 (VARC-3) consensus document [11]. Hospitalization for heart failure was defined as hospitalization due to typical symptoms and objective signs of worsening heart failure. The Society of Thoracic Surgeons (STS) risk score was calculated using the updated model released in 2018 [12,13].

All continuous data showed a skewed distribution and were thus expressed as median with interquartile range (IQR). Categorical variables were summarized as counts and percentages. Differences between both groups were assessed using the Mann-Whitney $\mathrm{U}$ test, $\chi^{2}$-test, and Fisher's exact test, as appropriate. Outcome data were evaluated using 
Kaplan-Meier curves and the log-rank test. For the Cox regression model, all factors linked to mortality in univariable $(p$-value $<0.25)$ were considered as candidate variables. The backward selection was based on the likelihood ratio criteria. Continuous variables were dichotomized to keep the Cox model simple. Cox regression results were presented as adjusted hazard ratios (HR) with 95\% confidence intervals (CI). The proportional hazard assumption was confirmed using weighted residuals. In order to minimize collinearity, covariables directly related to PVS including hemoglobin, hematocrit, and anemia were not included in the regression model. Statistical analyses were performed using R software, version 4.0.4 (URL: https: / / www.R-project.org/ (accessed on 27 July 2021)), and GraphPad PRISM, version 8 (GraphPad Software, San Diego, CA, USA). All tests were two-tailed, and a $p$-value $<0.05$ was considered statistically significant.

\section{Results}

\subsection{Baseline Characteristics}

A total of 859 TAVI patients were available for analysis. Based on the calculated PVS cutoff, 324 patients $(37.7 \%$ ) had a PVS $<-5.4 \%$ (no congestion), while 535 patients $(62.3 \%)$ had a PVS $\geq-5.4 \%$ (congestion). Compared to patients with PVS $<-5.4 \%$, the PVS $\geq-5.4 \%$ group was significantly older, had a higher proportion of female patients as well as higher STS Scores, higher levels of NT-proBNP, higher rates of impaired left ventricular ejection fraction (LVEF), higher prevalence of anemia, lower eGFR, lower hematocrit and hemoglobin, lower BMI and lower prevalence of dyslipidemia. Diuretics were more frequently prescribed in patients with a PVS $\geq-5.4 \%$ compared to the PVS $<-5.4 \%$ group (Table 1).

Table 1. Baseline characteristics and heart failure medication.

\begin{tabular}{|c|c|c|c|c|}
\hline & $\begin{array}{c}\text { Total } \\
(n=859)\end{array}$ & $\begin{array}{c}\text { PVS }<-5.4 \% \\
\quad(n=324)\end{array}$ & $\begin{aligned} \text { PVS } & \geq-5.4 \% \\
(n & =535)\end{aligned}$ & $p$-Value \\
\hline Age (years) & $81.9(78.7-85.8)$ & $81.0(77.6-84.1)$ & $82.8(79.5-86.9)$ & $<0.001$ \\
\hline Female, $n(\%)$ & $452(52.6)$ & $152(46.9)$ & $300(56.1)$ & 0.009 \\
\hline $\operatorname{BMI}\left(\mathrm{kg} / \mathrm{m}^{2}\right)$ & $26.2(23.9-29.6)$ & $28.9(25.9-32.0)$ & $25.0(22.7-27.7)$ & $<0.001$ \\
\hline Atrial fibrillation, $n(\%)$ & $373(43.4)$ & $134(41.4)$ & $239(44.7)$ & 0.342 \\
\hline $\mathrm{CAD}, n(\%)$ & $550(64.0)$ & $199(61.4)$ & $351(65.6)$ & 0.215 \\
\hline COPD, $n(\%)$ & $94(10.9)$ & $31(9.6)$ & $63(11.8)$ & 0.315 \\
\hline CVD, $n(\%)$ & $150(17.5)$ & $56(17.3)$ & $94(17.6)$ & 0.915 \\
\hline Diabetes mellitus, $n(\%)$ & $258(30.0)$ & $96(29.6)$ & $162(30.3)$ & 0.840 \\
\hline Dyslipidemia, $n(\%)$ & $431(50.2)$ & $177(54.6)$ & $254(47.5)$ & 0.042 \\
\hline Hypertension, $n(\%)$ & $759(88.4)$ & $286(88.3)$ & $473(88.4)$ & 0.951 \\
\hline NYHA class III or IV, $n(\%)$ & $612(71.2)$ & $219(67.6)$ & $393(73.5)$ & 0.067 \\
\hline $\mathrm{PAD}, n(\%)$ & $72(8.4)$ & $26(8.0)$ & $46(8.6)$ & 0.769 \\
\hline $\mathrm{PAH}, n(\%)$ & $115(13.4)$ & $46(14.2)$ & $69(12.9)$ & 0.588 \\
\hline Prev. cardiac surgery, $n(\%)$ & $126(14.7)$ & $54(16.7)$ & $72(13.5)$ & 0.198 \\
\hline STS-Score $(\%)$ & $3.7(2.4-5.5)$ & $2.9(2.1-4.6)$ & $4.2(2.6-6.3)$ & $<0.001$ \\
\hline Hematocrit (\%) & $0.36(0.32-0.39)$ & $0.40(0.38-0.42)$ & $0.34(0.31-0.36)$ & $<0.001$ \\
\hline Hemoglobin $(\mathrm{g} / \mathrm{dL})$ & $12.4(11.1-13.4)$ & $13.6(12.8-14.4)$ & $11.5(10.4-12.4)$ & $<0.001$ \\
\hline \multicolumn{5}{|l|}{ Anemia } \\
\hline Mild & $253(29.5)$ & $52(16.0)$ & $201(37.6)$ & $<0.001$ \\
\hline Moderate & $173(20.1)$ & $5(1.5)$ & $168(31.4)$ & $<0.001$ \\
\hline Severe & $5(0.6)$ & $0(0)$ & $5(0.9)$ & 0.081 \\
\hline Non-Anemia & $428(49.8)$ & $267(82.4)$ & $161(30.1)$ & $<0.001$ \\
\hline $\mathrm{eGFR}\left(\mathrm{mL} / \mathrm{min} / 1.73 \mathrm{~m}^{2}\right)$ & $54(40-67)$ & $59(48-70)$ & $51(37-63)$ & $<0.001$ \\
\hline NT-proBNP (pg/mL) & $1461(573-3462)$ & $986(445-2287)$ & $2102(704-4529)$ & $<0.001$ \\
\hline \multicolumn{5}{|l|}{ LVEF } \\
\hline$\geq 55 \%, n(\%)$ & $555(64.6)$ & $226(69.8)$ & $329(61.5)$ & 0.014 \\
\hline $45-54 \%, n(\%)$ & $162(18.9)$ & $52(16.0)$ & $110(20.6)$ & 0.101 \\
\hline $35-44 \%, n(\%)$ & $72(8.4)$ & $19(5.9)$ & $53(9.9)$ & 0.038 \\
\hline$<35 \%, n(\%)$ & $70(8.1)$ & $27(8.3)$ & $43(8.0)$ & 0.878 \\
\hline
\end{tabular}


Table 1. Cont.

\begin{tabular}{lcccc}
\hline & $\begin{array}{c}\text { Total } \\
(\boldsymbol{n}=\mathbf{8 5 9 )}\end{array}$ & $\begin{array}{c}\text { PVS }<-\mathbf{5 . 4} \% \\
(\boldsymbol{n}=\mathbf{3 2 4})\end{array}$ & $\begin{array}{c}\text { PVS } \geq-\mathbf{5 . 4 \%} \\
(\boldsymbol{n}=\mathbf{5 3 5})\end{array}$ & $\boldsymbol{p}$-Value \\
\hline AVA $\left(\mathrm{cm}^{2}\right)$ & $0.8(0.6-0.9)$ & $0.8(0.6-0.9)$ & $0.8(0.6-0.9)$ & 0.075 \\
MPG (mmHg) & $38(29-50)$ & $38(30-49)$ & $38(29-50)$ & 0.838 \\
MR III-IV, $n$ (\%) & $72(8.4)$ & $26(8.0)$ & $46(8.6)$ & 0.769 \\
TR III-IV, $n(\%)$ & $36(4.2)$ & $14(4.3)$ & $22(4.1)$ & 0.882 \\
Calculated actual PV (mL) & $2907(2621-3264)$ & $2951(2693-3321)$ & $2883(2566-3235)$ & 0.003 \\
Calculated ideal PV (mL) & $3000(2613-3393)$ & $3315(3000-3783)$ & $2800(2457-3120)$ & $<0.001$ \\
PVS (\%) & $-2.6(-8.6-4.1)$ & $-10.4(-14.0-7.5)$ & $1.8(-2.0-7.2)$ & $<0.001$ \\
Heart failure medication & & & $439(82.1)$ & 0.285 \\
ACE-I/ARB & $714(83.1)$ & $275(84.9)$ & $404(75.5)$ & 0.332 \\
Betablocker & $639(74.4)$ & $235(72.5)$ & $33(13.6)$ & 0.223 \\
MRA & $108(12.6)$ & $211(65.1)$ & $387(72.3)$ \\
Diuretics & $598(69.6)$ & 0.026 \\
\hline
\end{tabular}

Legend: ACE-I, angiotensin-converting enzyme inhibitor; ARB, angiotensin receptor blocker; AVA, aortic valve area; BMI, body mass index; CAD, coronary artery disease; COPD, chronic obstructive pulmonary disease; CVD, cerebrovascular disease; eGFR, estimated glomerular filtration rate; LVEF, left ventricular ejection fraction; MPG, mean pressure gradient; MR, mitral regurgitation; MRA, mineralocorticoid receptor antagonist; NT-proBNP, N-terminal Pro-B-Type Natriuretic Peptide; NYHA, New York Heart Association; PAD, peripheral artery disease; PAH, pulmonary arterial hypertension; Prev., previous; PV, plasma volume; PVS, plasma volume status; STS, Society of Thoracic Surgeons; TR, tricuspid regurgitation. Values are presented as median (interquartile range) or counts (percentages).

\subsection{Periprocedural Complications}

There was no statistically significant difference regarding the type of transcatheter heart valve used for the procedure. Periprocedural complications defined as individual endpoints of type 3 (life-threatening) bleeding, myocardial infarction, stroke with disability, acute kidney injury stage $3 / 4$, and new pacemaker implantation after TAVI did also not differ between both groups (Table 2).

Table 2. Procedural variables and outcomes.

\begin{tabular}{|c|c|c|c|c|}
\hline & $\begin{array}{c}\text { Total } \\
(n=859)\end{array}$ & $\begin{array}{c}\text { PVS }<-5.4 \% \\
\quad(n=324)\end{array}$ & $\begin{aligned} \text { PVS } & \geq-5.4 \% \\
(n & =535)\end{aligned}$ & $p$-Value \\
\hline Valve type & & & & 0.146 \\
\hline Self-expanding, $n(\%)$ & $433(50.4)$ & $153(47.2)$ & $280(52.3)$ & \\
\hline Balloon-expandable, $n(\%)$ & $426(49.6)$ & $171(52.8)$ & $255(47.7)$ & \\
\hline Procedural duration (min) & $50(40-63)$ & $49(40-61)$ & $49(40-65)$ & 0.302 \\
\hline Contrast medium (mL) & $84(70-105)$ & 85 (70-107) & $80(68-103)$ & 0.219 \\
\hline \multicolumn{5}{|l|}{ VARC-3 } \\
\hline New permanent pacemaker, $n(\%)$ & $101(11.8)$ & $43(13.3)$ & $58(10.8)$ & 0.284 \\
\hline Myocardial infarction, $n(\%)$ & $3(0.3)$ & $1(0.3)$ & $2(0.4)$ & $>0.999$ \\
\hline AKIN stage $3 / 4, n(\%)$ & $9(1.0)$ & $2(0.6)$ & $7(1.3)$ & 0.496 \\
\hline Type 3 (life-threatening) bleeding, $n$ (\%) & $21(2.4)$ & $4(1.2)$ & $17(3.2)$ & 0.108 \\
\hline Stroke with disability, $n(\%)$ & $3(0.3)$ & $1(0.3)$ & $2(0.4)$ & $>0.999$ \\
\hline Primary composite outcome, $n(\%)$ & $163(19.0)$ & $42(13.0)$ & $121(22.6)$ & $<0.001$ \\
\hline All-cause mortality, $n(\%)$ & $110(12.8)$ & $22(6.8)$ & $88(16.4)$ & $<0.001$ \\
\hline Heart failure hospitalization, $n(\%)$ & $77(9.0)$ & $21(6.5)$ & $56(10.5)$ & 0.048 \\
\hline
\end{tabular}

Legend: AKIN, Acute Kidney Injury Network; PVS, plasma volume status; VARC-3, Valve Academic Research Consortium-3. Values are presented as median (interquartile range) or counts (percentages).

\subsection{Clinical Outcome during Long-Term Follow-Up}

The primary composite outcome (all-cause mortality or heart failure hospitalization) occurred in $121 / 535$ patients $(22.6 \%)$ in the PVS $\geq-5.4 \%$ group compared to $42 / 324$ patients $(13.0 \%)$ with a PVS $<-5.4 \%$ (Table 1, Figure 1). Furthermore, the PVS $\geq-5.4 \%$ group had higher rates of both secondary endpoints of all-cause mortality $(16.4 \% \mathrm{vs} .6 .8 \%$, $p<0.001)$ and heart failure hospitalization $(10.5 \%$ vs. $6.5 \%, p=0.031$; Table 1 , Figure $2 \mathrm{~A}, \mathrm{~B})$. In univariable Cox regression analysis, PVS was significantly associated with the primary endpoint (HR 1.99, 95\%, CI 1.39-2.84, $p<0.001$ ). After multivariable adjustment for other 
variables, PVS remained a significant predictor of the composite of all-cause mortality or heart failure hospitalization (HR 1.53, 95\% CI 1.05-2.22, $p=0.026$; Table 3).

Primary composite endpoint

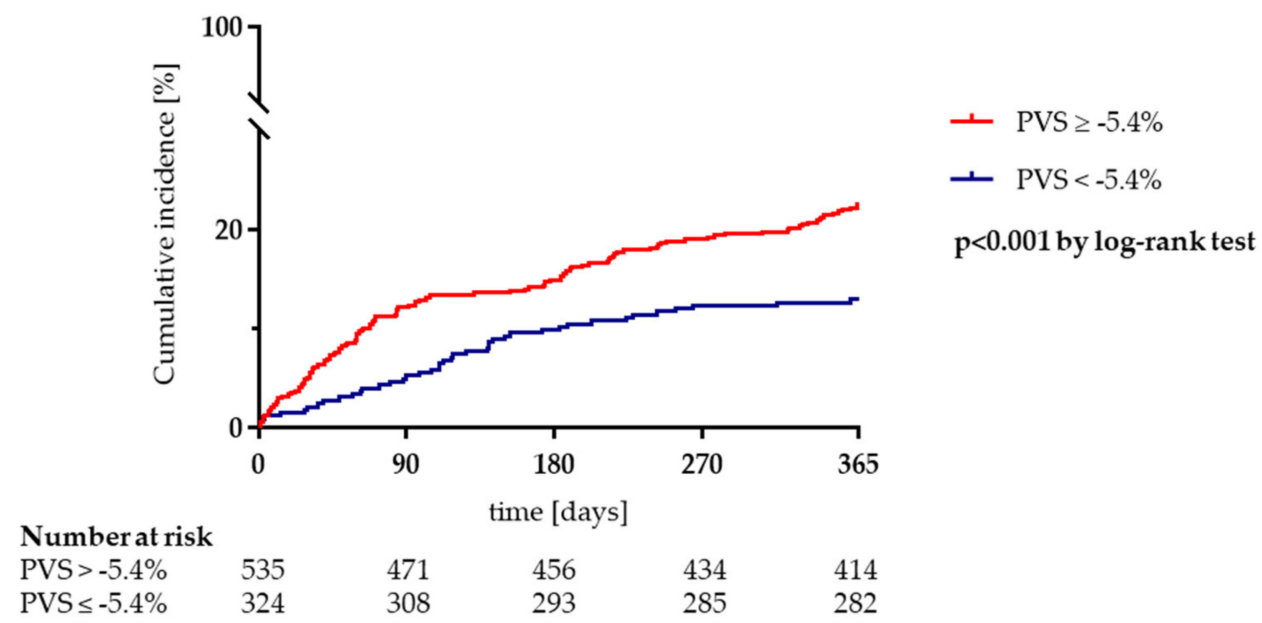

Figure 1. Elevated plasma volume status (PVS) is associated with the primary composite endpoint of all-cause mortality or heart failure hospitalization after transcatheter aortic valve implantation. Legend: Kaplan-Meier survival curves for the primary endpoint comparing patients with a PVS $\geq-5.4 \%$ (congestion) to patients with a PVS $<-5.4 \%$ (no congestion).

All-cause mortality

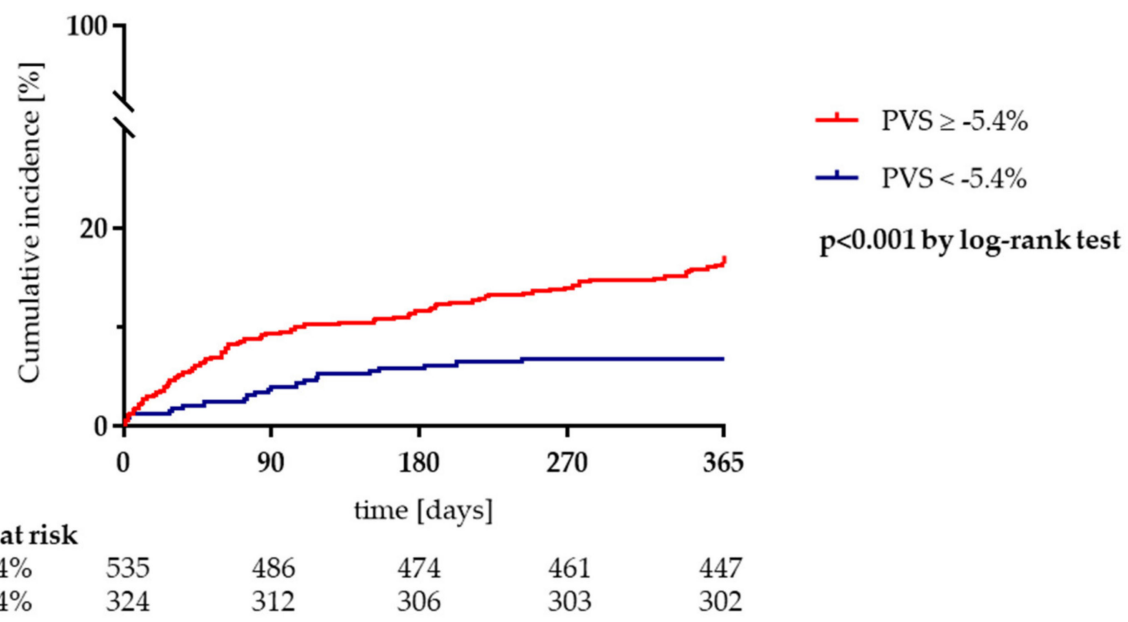

$\begin{array}{llllll}\text { PVS }>-5.4 \% & 535 & 486 & 474 & 461 & 447 \\ \text { PVS } \leq-5.4 \% & 324 & 312 & 306 & 303 & 302\end{array}$

(A) All-cause mortality

Figure 2. Cont. 


\section{Heart failure hospitalization}

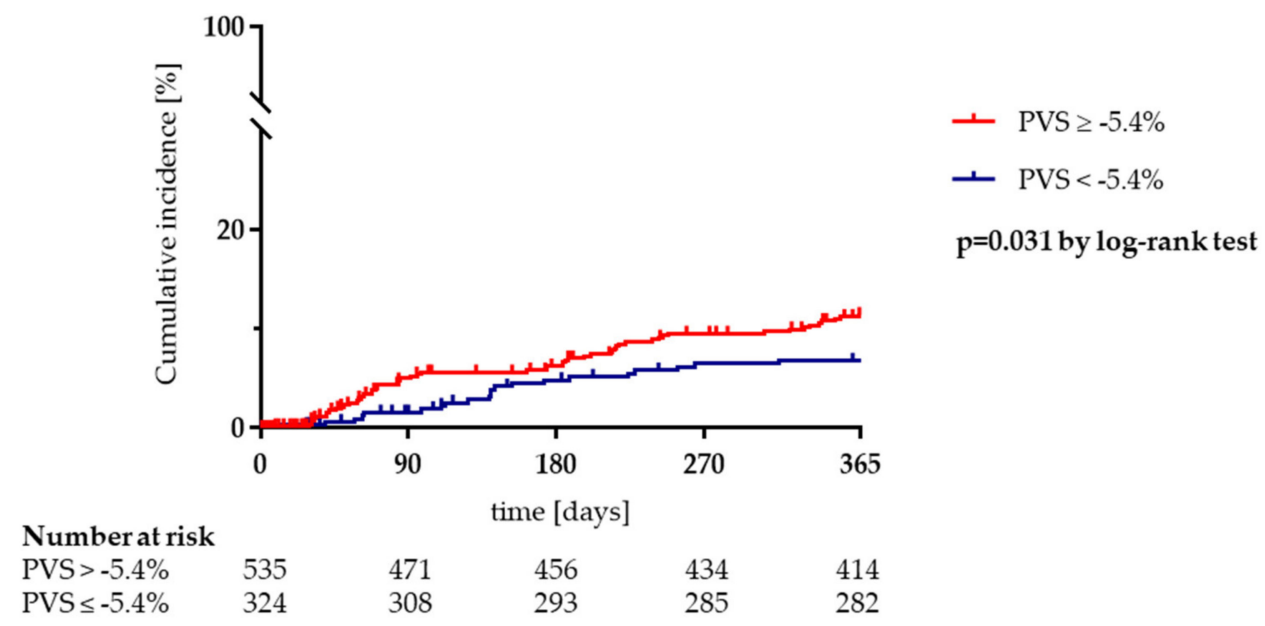

(B) Heart failure hospitalization

Figure 2. Elevated plasma volume status (PVS) is associated with adverse outcomes after transcatheter aortic valve implantation. (A) All-cause mortality. (B) Heart failure hospitalization. Legend: Kaplan-Meier survival curves for the secondary endpoints of all-cause mortality and heart failure hospitalization comparing patients with a PVS $\geq-5.4 \%$ (congestion) to patients with a PVS $<-5.4 \%$ (no congestion).

Table 3. Cox regression analysis for the primary composite endpoint of all-cause mortality or heart failure hospitalization.

\begin{tabular}{|c|c|c|c|c|}
\hline Variable & HR $(95 \%$ CI) & $p$-Value & HR $(95 \%$ CI $)$ & $p$-Value \\
\hline $\mathrm{PVS} \geq-5.4 \%$ & $1.99(1.39-2.84)$ & $<0.001$ & $1.53(1.05-2.22)$ & 0.026 \\
\hline Atrial fibrillation & $1.70(1.25-2.31)$ & $<0.001$ & & \\
\hline Age > median (81.9 years) & $1.27(0.93-1.73)$ & 0.132 & & \\
\hline BMI $>$ median $\left(26.2 \mathrm{~kg} / \mathrm{m}^{2}\right)$ & $0.66(0.48-0.90)$ & 0.008 & & \\
\hline STS score $>$ median $(3.7 \%)$ & $2.23(1.61-3.08)$ & $<0.001$ & $1.67(1.17-2.38)$ & 0.005 \\
\hline COPD & $1.58(1.03-2.42)$ & 0.036 & $1.54(0.99-2.39)$ & 0.056 \\
\hline NT-proBNP > median $(1461 \mathrm{pg} / \mathrm{mL})$ & $1.94(1.41-2.67)$ & $<0.001$ & $1.48(1.06-2.09)$ & 0.023 \\
\hline $\mathrm{eGFR}<60 \mathrm{~mL} / \mathrm{min} / 1.73 \mathrm{~cm}^{2}$ & $1.85(1.29-2.65)$ & $<0.001$ & & \\
\hline LVEF $<55 \%$ & $1.73(1.27-2.35)$ & $<0.001$ & & \\
\hline TR III-IV & $3.37(2.04-5.57)$ & $<0.001$ & $2.87(1.72-4.80)$ & $<0.001$ \\
\hline MR III-IV & $2.36(1.55-3.59)$ & $<0.001$ & & \\
\hline PAH & $1.55(1.04-2.30)$ & 0.030 & & \\
\hline AKIN stage $3 / 4$ & $10.10(4.72-21.70)$ & $<0.001$ & $8.50(3.91-18.51)$ & $<0.001$ \\
\hline Myocardial infarction & $5.11(1.27-20.60)$ & 0.022 & $6.12(1.47-25.40)$ & 0.013 \\
\hline Stroke with disability & $7.73(1.92-31.20)$ & 0.004 & & \\
\hline Type 3 (life-threatening) bleeding & $4.60(2.55-8.28)$ & $<0.001$ & $6.34(3.50-11.49)$ & $<0.001$ \\
\hline
\end{tabular}

Legend: AKIN, Acute Kidney Injury Network; BMI, body mass index; COPD, chronic obstructive pulmonary disease; eGFR, estimated glomerular filtration rate; LVEF, left ventricular ejection fraction; MR, mitral regurgitation; NT-proBNP, N-terminal Pro-B-Type Natriuretic Peptide; PAH, pulmonary arterial hypertension; PVS, plasma volume status; STS, Society of Thoracic Surgeons; TR, tricuspid regurgitation. Results are presented as adjusted hazard ratios (HR) with 95\% confidence intervals (CI).

\section{Discussion}

This study found that calculated PVS as a marker of hypervolemia was significantly associated with all-cause mortality and heart failure hospitalization in patients undergoing TAVI.

In our study, $62.3 \%$ of patients had a preprocedural PVS $\geq-5.4 \%$ reflecting relevant (subclinical) congestion. This relatively high incidence of hypervolemia as well as the ROC-derived cutoff for PVS of $-5.4 \%$ in TAVI patients is consistent with previously published reports [14]. In another study using a PVS cut-off value of $-4 \%$, an elevated 
PVS was present in $59.6 \%$ of patients admitted for TAVI [15]. Compared to patients with PVS $<-5.4 \%$, patients with a PVS $\geq-5.4 \%$ in our study were older and had multiple co-morbidities. Again, this was consistent with previously published investigations, where elevated PVS was associated with increased comorbidities in patients undergoing TAVI [14-17]. The lower BMI in patients with a PVS $\geq-5.4 \%$ was most probably a result of malnutrition and frailty, which are associated with an increased risk of all-cause mortality in patients undergoing TAVI $[16,18]$. In our study, the median calculated PVS was $-2.6 \%$ $(-8.6-4.1 \%)$ which is in line with previously reported PVS in the context of TAVI [14]. Notably, PVS values in TAVI patients seem to be higher than in patients with chronic heart failure [8]. This finding indicates that patients with severe symptomatic AS may suffer from unrecognized hypervolemia and subclinical congestion to a greater extent compared to patients with chronic heart failure. This may be explained by the typical clinical profile of the TAVI population including advanced age, high prevalence of comorbidities, and suboptimal heart failure medication in elderly patients [19]. In our study, patients with a PVS $\geq-5.4 \%$ showed higher rates of diuretic therapy, while there was no significant difference in prognostic heart failure medication. This finding highlights the potential role of PVS as a tool to optimize medical treatment.

During follow-up, both mortality and heart failure hospitalization were significantly higher in patients with PVS $\geq-5.4 \%$ compared to patients with PVS $<-5.4 \%(p<0.001$ and $p=0.031$, respectively; Figure 2A,B). Consistently, other studies showed adverse outcomes in TAVI patients with elevated PVS. Maznyczka et al. reported that a PVS $>0 \%$ was linked to a two-fold risk for mortality as well as prolonged ICU and hospital stay [14]. Shimura et al. reported a significantly higher all-cause mortality and heart failure hospitalization rate in the high-PVS group than in the low-PVS group [17]. In addition, patients with high PVS and NYHA I/II had a worse prognosis than those with low PVS and NYHA III/IV. Adlbrecht et al. reported that patients with a high PVS did not only demonstrate a substantially impaired long-term survival during follow-up but were also at increased risk for a 30-day composite of all-cause mortality, stroke, life-threatening bleeding, acute kidney injury, coronary artery obstruction requiring intervention, major vascular complication and valve-related dysfunction requiring repeat procedure [15]. The prognostic significance of PVS was also previously reported in patients with heart failure. In an analysis of 3414 patients with heart failure with preserved ejection fraction, higher calculated estimates of PVS were independently associated with an elevated risk of long-term clinical outcomes, and particularly, heart failure hospitalization [20]. In an analysis of 186 patients who received a continuous-flow left ventricular assist device, high PVS was associated with higher mortality during follow-up [21].

Importantly, previous studies investigating calculated PVS have not reported the prevalence of anemia $[14,15,17]$. Based on WHO definitions, anemia $(<12.0 \mathrm{~g} / \mathrm{dL}$ in women; $<13.0 \mathrm{~g} / \mathrm{dLs}$ in men) was prevalent in $50.2 \%$ of the total population in our study $(69.9 \%$ in the PVS $\geq-5.4 \%$ groups compared to $17.6 \%$ the PVS $<-5.4 \%$ group, $p<0.001$ ). This was mostly attributed to mild and moderate forms of anemia [22]. While anemia is known to be multifactorial in patients with severe AS, hemodilution due to congestion is likely to have had a significant impact on the high prevalence of anemia in patients with PVS $\geq-5.4 \%$ [23-25]. As was the case in previous studies, our analysis is unable to differentiate between "true" anemia and anemia due to hemodilution in patients with congestion. Thus, future studies should focus on the close relationship between anemia and PVS in order to correct for confounding effects.

It has been previously suggested that volume overload associated with elevated PVS might add to the pressure overload on the stiff, non-compliant ventricle in severe AS, leading to a higher risk of pulmonary and systemic edema, global hypoperfusion, and adverse outcomes after TAVI [14]. Thus, calculated PVS could be a simple tool to guide fluid management and medical treatment including diuretic therapy in patients with heart failure. Similarly, NT-proBNP has been previously proposed as a simple marker to guide therapy in the context of heart failure and TAVI $[26,27]$. Additionally, a number of 
cardiovascular biomarkers, such as high-sensitivity Troponin T, soluble ST2, and GDF-15 have also been studied in the context of TAVI and are associated with outcomes in patients undergoing TAVI [28]. Using PVS in patients with severe AS and optimizing heart failure treatment in addition to TAVI may result in more favorable outcomes in this vulnerable patient group. Prospective randomized trials are needed to study the utility of PVS as part of an integrated approach for improved risk stratification and management of TAVI patients.

There are several study limitations that have to be acknowledged. First, this is a singlecenter study which may limit the conclusions that can be drawn from the analysis. Second, in line with previous studies, hemoglobin/hematocrit and anemia were not included in the Cox regression model in order to minimize collinearity. However, comorbidities such as frailty, heart failure, and chronic kidney disease are known to be closely associated with hemoglobin concentrations, which may have significantly influenced PVS [29]. Third, as anemia and PVS are closely intertwined, this study is unable to differentiate between true anemia and anemia caused by hemodilution. Thus, anemia potentially remains a major confounding factor. Fourth, the relative low HR for PVS in the Cox regression analysis indicates that PVS should only be used as part of an integrative approach. Fifth, additional endpoints such as heart failure symptoms and physical capacity were not accounted for. Sixth, factors affecting PVS, such as blood transfusions and extensive heart failure therapy during a hospital stay, were not taken into consideration during the calculation of PVS. Finally, ePV in this study was not validated by the measured PV. However, ePV has been shown to correlate well with PV levels measured using gold-standard radioisotope assays $[8,26]$.

\section{Conclusions}

Elevated PVS was an independent predictor of all-cause mortality and heart failure hospitalization within 1 year after TAVI. Future trials are necessary to determine the potential role of PVS as part of an integrative strategy towards improved risk stratification and therapeutic management of patients undergoing TAVI.

Author Contributions: Conceptualization, H.S., M.S. (Mohammed Saad), J.F., C.K., D.F.; methodology, H.S., M.S. (Mostafa Salem), K.A.; software, H.S., M.S. (Mohammed Saad), G.L., D.F.; validation, J.F., T.P., C.K.; formal analysis, H.S., M.S. (Mohammed Saad), K.A., D.F.; investigation, H.S., M.S. (Mohammed Saad), K.A., T.P., G.L., C.K.; resources, H.S., M.S. (Mohammed Saad), J.F., T.P.; data curation, H.S., M.S. (Mohammed Saad), M.S. (Mohamed Salem), G.L.; writing—original draft preparation, H.S., M.S. (Mohammed Saad), K.A.; writing—review and editing, M.S. (Mostafa Salem), J.F., T.P., G.L., C.K., D.F.; visualization, H.S., K.A.; supervision, C.K., D.F.; project administration, H.S., M.S. (Mohammed Saad), D.F. All authors have read and agreed to the published version of the manuscript.

Funding: This research received no external funding.

Institutional Review Board Statement: The study was conducted according to the guidelines of the Declaration of Helsinki, and approved by the Ethics Committee of the University of Kiel (protocol code D 529/16).

Informed Consent Statement: Informed consent was obtained from all subjects involved in the study.

Data Availability Statement: The datasets for this study will not be made available to other researchers due to data protection reasons. However, calculation of PVS is simple and easily reproducible, and we encourage scientists to validate our findings in other TAVI cohorts.

Conflicts of Interest: G.L. is a consultant for Edwards Lifesciences, Medtronic, Boston Scientific and Abbott. C.K. received speaker's honoraria from Medtronic. D.F. is a consultant for Edwards Lifesciences and Medtronic and has received research funding from Edwards Lifesciences. All other authors have no commercial or financial relationships that could be construed as a potential conflict of interest. 


\section{References}

1. Carroll, J.D.; Mack, M.J.; Vemulapalli, S.; Herrmann, H.C.; Gleason, T.G.; Hanzel, G.; Deeb, G.M.; Thourani, V.H.; Cohen, D.J.; Desai, N.; et al. STS-ACC TVT Registry of Transcatheter Aortic Valve Replacement. J. Am. Coll. Cardiol. 2020, 76, 2492-2516. [CrossRef]

2. Writing Committee Members; Otto, C.M.; Nishimura, R.A.; Bonow, R.O.; Carabello, B.A.; Erwin, J.P., III; Gentile, F.; Jneid, H.; Krieger, E.V.; Mack, M.; et al. 2020 ACC/AHA Guideline for the Management of Patients With Valvular Heart Disease: A Report of the American College of Cardiology/American Heart Association Joint Committee on Clinical Practice Guidelines. J. Am. Coll. Cardiol. 2021, 77, e25-e197. [CrossRef] [PubMed]

3. Nitsche, C.; Kammerlander, A.A.; Koschutnik, M.; Sinnhuber, L.; Forutan, N.; Eidenberger, A.; Donà, C.; Schartmueller, F.; Dannenberg, V.; Winter, M.; et al. Fluid overload in patients undergoing TAVR: What we can learn from the nephrologists. ESC Heart Fail. 2021, 8, 1408-1416. [CrossRef]

4. Binanay, C.; Califf, R.M.; Hasselblad, V.; O'Connor, C.M.; Shah, M.R.; Sopko, G.; Stevenson, L.W.; Francis, G.S.; Leier, C.V.; Miller, L.W.; et al. Evaluation Study of Congestive Heart Failure and Pulmonary Artery Catheterization Effectiveness. JAMA 2005, 294, 1625-1633. [CrossRef]

5. Miller, W.L.; Mullan, B.P. Volume Overload Profiles in Patients with Preserved and Reduced Ejection Fraction Chronic Heart Failure. JACC Heart Fail. 2016, 4, 453-459. [CrossRef]

6. Gibson, J.G.; Seligman, A.M.; Peacock, W.C.; Aub, J.C.; Fine, J.; Evans, R.D. The distribution of red cells and plasma in large and minute vessels of the normal dog, determined by radioactive isotopes of iron and iodine 1. J. Clin. Investig. 1946, 25, 848-857. [CrossRef]

7. Martens, P.; Nijst, P.; Dupont, M.; Mullens, W. The Optimal Plasma Volume Status in Heart Failure in Relation to Clinical Outcome. J. Card. Fail. 2019, 25, 240-248. [CrossRef]

8. $\quad$ Ling, H.Z.; Flint, J.; Damgaard, M.; Bonfils, P.K.; Cheng, A.; Aggarwal, S.; Velmurugan, S.; Mendonca, M.; Rashid, M.; Kang, S.; et al. Calculated plasma volume status and prognosis in chronic heart failure. Eur. J. Heart Fail. 2015, 17, 35-43. [CrossRef]

9. Hakim, R.M. Plasmapheresis. In Handbook of Dialysis, 3rd ed.; Daugirdas, J.T., Blake, P.G., Ing, T.S., Eds.; Lippincott, Williams and Wilkins: Philadelphia, PA, USA, 2001; p. 236.

10. Longo, D. Table 218: Body fluids and other mass data. In Harrison's Principles of Internal Medicine, 18th ed.; Longo, D.L., Fauci, A.S., Kasper, D.L., Hauser, S.L., Jameson, J.L., Loscalzo, J., Eds.; McGraw-Hill: New York, NY, USA, 2011; p. A-1.

11. VARC-3 Writing Committee; Généreux, P.; Piazza, N.; Alu, M.C.; Nazif, T.; Hahn, R.T.; Pibarot, P.; Bax, J.J.; A Leipsic, J.; Blanke, P.; et al. Valve Academic Research Consortium 3: Updated endpoint definitions for aortic valve clinical research. Eur. Heart J. 2021, 42, 1825-1857. [CrossRef]

12. Shahian, D.M.; Jacobs, J.P.; Badhwar, V.; Kurlansky, P.A.; Furnary, A.P.; Cleveland, J.C.; Lobdell, K.W.; Vassileva, C.; von Ballmoos, M.C.W.; Thourani, V.H.; et al. The Society of Thoracic Surgeons 2018 Adult Cardiac Surgery Risk Models: Part 1-Background, Design Considerations, and Model Development. Ann. Thorac. Surg. 2018, 105, 1411-1418. [CrossRef] [PubMed]

13. O’Brien, S.M.; Feng, L.; He, X.; Xian, Y.; Jacobs, J.P.; Badhwar, V.; Kurlansky, P.A.; Furnary, A.P.; Cleveland, J.C.; Lobdell, K.W.; et al. The Society of Thoracic Surgeons 2018 Adult Cardiac Surgery Risk Models: Part 2-Statistical Methods and Results. Ann. Thorac. Surg. 2018, 105, 1419-1428. [CrossRef] [PubMed]

14. Maznyczka, A.M.; Barakat, M.; Aldalati, O.; Eskandari, M.; Wollaston, A.; Tzalamouras, V.; Dworakowski, R.; Deshpande, R.; Monaghan, M.; Byrne, J.; et al. Calculated plasma volume status predicts outcomes after transcatheter aortic valve implantation. Open Heart 2020, 7, e001477. [CrossRef]

15. Adlbrecht, C.; Piringer, F.; Resar, J.; Watzal, V.; Andreas, M.; Strouhal, A.; Hasan, W.; Geisler, D.; Weiss, G.; Grabenwöger, M.; et al The impact of subclinical congestion on the outcome of patients undergoing transcatheter aortic valve implantation. Eur. J. Clin. Investig. 2020, 50, e13251. [CrossRef] [PubMed]

16. Afilalo, J.; Lauck, S.; Kim, D.H.; Lefèvre, T.; Piazza, N.; Lachapelle, K.; Martucci, G.; Lamy, A.; Labinaz, M.; Peterson, M.D.; et al. Frailty in Older Adults Undergoing Aortic Valve Replacement. J. Am. Coll. Cardiol. 2017, 70, 689-700. [CrossRef]

17. Shimura, T.; Yamamoto, M.; Yamaguchi, R.; Adachi, Y.; Sago, M.; Tsunaki, T.; Kagase, A.; Koyama, Y.; Otsuka, T.; Yashima, F.; et al. Calculated plasma volume status and outcomes in patients undergoing transcatheter aortic valve replacement. ESC Heart Fail. 2021, 8, 1990-2001. [CrossRef]

18. Seoudy, H.; Al-Kassou, B.; Shamekhi, J.; Sugiura, A.; Frank, J.; Saad, M.; Bramlage, P.; Seoudy, A.K.; Puehler, T.; Lutter, G.; et al. Frailty in patients undergoing transcatheter aortic valve replacement: Prognostic value of the Geriatric Nutritional Risk Index. J. Cachex Sarcopenia Muscle 2021, 12, 577-585. [CrossRef] [PubMed]

19. Komajda, M.; Hanon, O.; Hochadel, M.; Lopez-Sendon, J.L.; Follath, F.; Ponikowski, P.; Harjola, V.-P.; Drexler, H.; Dickstein, K.; Tavazzi, L.; et al. Contemporary management of octogenarians hospitalized for heart failure in Europe: Euro Heart Failure Survey II. Eur. Heart J. 2008, 30, 478-486. [CrossRef]

20. Grodin, J.L.; Philips, S.; Mullens, W.; Nijst, P.; Martens, P.; Fang, J.C.; Drazner, M.H.; Tang, W.W.; Pandey, A. Prognostic implications of plasma volume status estimates in heart failure with preserved ejection fraction: Insights from TOPCAT. Eur. J. Heart Fail. 2019, 21, 634-642. [CrossRef]

21. Imamura, T.; Narang, N.; Combs, P.; Siddiqi, U.; Mirzai, S.; Stonebraker, C.; Bullard, H.; Simone, P.; Jeevanandam, V. Impact of plasma volume status on mortality following left ventricular assist device implantation. Artif. Organs 2021, 45, 587-592. [CrossRef] [PubMed] 
22. Haemoglobin Concentrations for the Diagnosis of Anaemia and Assessment of Severity. Vitamin and Mineral Nutrition Information System; WHO/NMH/NHD/MNM/11.1; World Health Organization: Geneva, Switzerland, 2011; Available online: http: //www.who.int/vmnis/indicators/haemoglobin.pdf (accessed on 18 July 2021).

23. Nagao, K.; CURRENT AS Registry Investigators; Taniguchi, T.; Morimoto, T.; Shiomi, H.; Ando, K.; Kanamori, N.; Murata, K.; Kitai, T.; Kawase, Y.; et al. Anemia in Patients with Severe Aortic Stenosis. Sci. Rep. 2019, 9, 1924. [CrossRef]

24. Androne, A.-S.; Katz, S.D.; Lund, L.; LaManca, J.; Hudaihed, A.; Hryniewicz, K.; Mancini, D.M. Hemodilution Is Common in Patients with Advanced Heart Failure. Circulation 2003, 107, 226-229. [CrossRef]

25. Otto, J.; Plumb, J.; Clissold, E.; Kumar, S.B.; Wakeham, D.J.; Schmidt, W.; Grocott, M.; Richards, T.; Montgomery, H.E. Hemoglobin concentration, total hemoglobin mass and plasma volume in patients: Implications for anemia. Haematologica 2017, 102, 1477-1485. [CrossRef]

26. Felker, G.M.; Anstrom, K.J.; Adams, K.F.; Ezekowitz, J.A.; Fiuzat, M.; Houston-Miller, N.; Januzzi, J.L.; Mark, D.B.; Piña, I.L.; Passmore, G.; et al. Effect of Natriuretic Peptide-Guided Therapy on Hospitalization or Cardiovascular Mortality in High-Risk Patients With Heart Failure and Reduced Ejection Fraction. JAMA 2017, 318, 713-720. [CrossRef]

27. Seoudy, H.; Frank, J.; Neu, M.; Güßefeld, N.; Klaus, Y.; Freitag-Wolf, S.; Lambers, M.; Lutter, G.; Dempfle, A.; Rangrez, A.Y.; et al. Periprocedural Changes of NT-proBNP Are Associated with Survival After Transcatheter Aortic Valve Implantation. J. Am. Heart Assoc. 2019, 8, e010876. [CrossRef]

28. Oury, C.; Nchimi, A.; Lancellotti, P.; Bergler-Klein, J. Can Blood Biomarkers Help Predicting Outcome in Transcatheter Aortic Valve Implantation? Front. Cardiovasc. Med. 2018, 5, 31. [CrossRef] [PubMed]

29. Wu, P.Y.; Chao, C.-T.; Chan, D.-C.; Huang, J.-W.; Hung, K.-Y. Contributors, risk associates, and complications of frailty in patients with chronic kidney disease: A scoping review. Ther. Adv. Chronic Dis. 2019, 10. [CrossRef] [PubMed] 